\title{
Las nuevas corrientes geográficas y didácticas y su repercusión en el proceso de enseñanza-aprendizaje de la Geografía (el caso de la Geografía Urbana)
}

\author{
José Miguel Santos Preciado*
}

\begin{abstract}
RESUMEN SUMMARY
Las tendencias de la ciencia geográfica y los modelos psicopedagógicos del aprendizaje han fragmentado el proceso didáctico de la enseñanza de la Geografia, dificultando la elaboración de un currículum geográfico unitario. La aplicación de esta problemática al campo de la Geografía Urbana, permite comprobar, mediante diversos ejemplos, integrados en los principales paradigmas del pensamiento geográfico contemporáneo, cómo los aspectos teóricos, metodológicos y de transmisión didáctica de esta materia de estudio, se hallan fraccionados en areas de conocimiento dispar, derivados de un origen epistemológico y de modelo didáctico diferenciado.

The trends in geographical science and the psychoeducational models of learning have divided the didactic process of Geography teaching, making it more difficult to agree on a single Geography curriculum. The application of these problems to the field of Urban Geography, throuhg various examples integrated in the principal paradigms of contemporary geographical thought, allows a study to be made of how aspects of theory, metodology and didactic transmission of this study subject are divided into separate areas of knowledge, derived from different epistemological sources, and from different didactic models.
\end{abstract}

* UNED. 


\section{INTRODUCCIÓN}

La transmisión de conocimientos de cualquier materia objeto de estudio presenta múltiples problemas de difícil solución. Una mínima planificación del proceso de enseñanza-aprendizaje exige la definición y posterior respuesta a un conjunto de interrogantes:

- ¿Qué enseñar?, que requiere plantearse los objetivos a los que se dirige el proceso didáctico, encuadrado en un proyecto global de aprendizaje, así como los contenidos que den respuesta a los mismos.

- ¿Cómo enseñar?, que equivale a concretar la metodología, técnicas e instrumentos de trabajo, articulados en un curriculum académico.

- ¿Para que enseñar?, en relación con la valoración social del contenido educativo.

- ¿Cómo evaluar?, o comprobación de la efectividad del proceso diseñado.

En el caso concreto de la Geografía, la complejidad de su didáctica específica se deriva, además, de la naturaleza de la materia a transmitir, que ha sido motivo de controversia sobre su objeto de estudio e identidad. Su idiosincrasia, como ciencia de síntesis, puente entre las ciencias naturales y sociales, ha abierto múltiples interrogantes sobre su contenido.

No es difícil observar, en nuestro país, como en los de la misma órbita cultural (aunque quizás en el nuestro con un cierto retraso), como en el campo de la docencia geográfica se ha evolucionado, desde la descripción corológica (descripción de lugares concretos, en un marco donde la Geografía podría ser considerada como la hermana menor de la Historia) hasta la explicación espacial, para comprender que ha existido un cambio profundo de objetivos, contenidos y actitudes valorativas y procedimentales. Los motivos de este profundo cambio han afectado, decisivamente, los objetivos, metodología y recursos didácticos y tienen que ver con factores de muy diversa indole (Capel, H., Luis, A. Y Urteaga, L., 1987):

- Las transformaciones económicas y sociales, espectaculares durante los últimos años. Entre las más importantes podríamos destacar:

- El crecimiento de la población mundial y el problema de los recursos.

- El desarrollo de la tecnología. La conquista del espacio ha modificado, sustancialmente, las fuentes originarias de las imágenes geográficas, mediante el nuevo campo de la teledetección. 
- La revolución de los sistemas de transportes y comunicaciones, circunstancia que ha conllevado la mundialización de las relaciones humanas y el acercamiento de las culturas.

- La profundización de las desigualdades existentes entre los paises desarrollados y subdesarrollados.

- La revolución informática.

- La degradación medioambiental, que ha originado una nueva problemática en la relación hombre-medio.

- La evolución del pensamiento geográfico, que ha tenido una gran repercusión en el nacimiento de las nuevas geografías y en el progreso, desde la etapa precientífica o preinstitucional a la moderna (con el nacimiento del ambientalismo o determinismo geográfico y del historicismo 0 posibilismo) y contemporánea, posterior a la segunda guerra mundial, donde la oposición positivismo/historicismo ha cobrado una nueva dimensión, con la aparición de nuevos paradigmas: neopositivistas, behavioristas o de la percepción, radicales y humanistas (Johnston, R. J. 1979).

- La evolución experimentada por las ciencias de la educación, que podríamos concretar en:

- La democratización de la enseñanza, comprometida, en el momento presente, con la totalidad de la población.

- La racionalización de la enseñanza, que ha originado la reforma curricular (que algunos denominan, incluso, de revolución), mediante la estructuración de los conocimientos, el plan de instrucción, las experiencias del aprendizaje y la solución de los problemas planteados.

- Finalmente, la aparición de nuevas corrientes y modelos didácticos, relacionados con la Psicologia Evolutiva y la aparición de corrientes conductistas, cognoscitivas y ambientalistas.

Estos trascendentales hechos han condicionado, decisivamente, la definición del proceso de enseñanza-aprendizaje de la Geografía. De todos ellos, quizás sean el marco epistemológico de la ciencia y el marco perceptual de la comprensión de la materia enseñada, derivado de las categorias mentales de los alumnos, ambos cambiantes en el tiempo (en este último según la edad de los alumnos), los que delimitan conceptos, problemas y metodologias específicos, que adquieren asi una identidad propia en el marco teórico donde se desarrollan.

Estas circunstancias han fragmentado los elementos del proceso didáctico, hasta hacer difícil la elaboración de un currículum geográfico uni- 
tario, mediatizado como está por la variedad de corrientes epistemológicas de la ciencia geográfica, así como por las tendencias educativas, orientadoras del aprendizaje. A modo de muestra, vamos a desarrollar, brevemente, en próximos apartados, la influencia de ambos factores y su variedad de opciones, para a continuación observar su influencia en la delimitación del curriculum didáctico de la Geografía Urbana, uno de los campos donde la ciencia geográfica ha cristalizado con mayor entidad.

\section{LAS PRINCIPALES CORRIENTES DEL PENSAMIENTO GEOGRÁFICO}

El concepto de paradigma, tal como fue definido por Khun (Khun, T.S., 1979), puede servirnos de gran utilidad para comprender las principales etapas del pensamiento geográfico. Según Khun, el conocimiento científico no avanza de manera lineal y acumulativa, sino dentro de un paradigma o plataforma, de carácter histórico, que permite, durante un periodo de tiempo, definir los problemas y métodos legítimos en el campo de la investigación. La ciencia no sería, por tanto, tan aséptica como muchos creen, sino que necesitaría de un andamiaje particular, a partir del cual elaborar conceptos, métodos y teorías. A esta visión relativista del conocimiento científico habría que añadir su carácter dinámico. A cada etapa de la ciencia "normal" le sucedería otra, que trataría de insertarse socialmente, aprovechando una coyuntura ideológica favorable.

\subsection{Los paradigmas geográficos de la etapa moderna}

Las principales corrientes del pensamiento geográfico pueden ser trazadas con respecto a la referencia temporal de la segunda guerra mundial. La Geografía anterior a la aparición de la denominada "Nueva Geografía» se correspondería con los dos movimientos que dominaron las ciencias sociales, desde mediados del siglo pasado y que, de alguna manera, no han dejado de estar siempre presentes (aunque bajo otras coordenadas) en la problemática actual; nos referimos a la oposición existente entre el positivismo y el historicismo.

\section{La corriente ambientalista}

En el crisol de cada una de estas dos grandes corrientes epistemológicas y teóricas se han ido fraguando los dos principales paradigmas de la 
Geografía clásica: el determinismo y el posibilismo, también designados por otros como ambientalismo e historicismo.

El ambientalismo y el positivismo que lo sustenta surgen a mediados del siglo $x \mid x$, llegando a impregnar, profundamente, el método científico de aquellos años. El positivismo puede definirse, tanto como método científico como concepción filosófica, aspectos, ambos, muy relacionados entre sí.

Como método científico, el positivismo puede definirse como un empirismo inductivo racionalista, que rompe con las ideas del idealismo y romanticismo hasta entonces imperantes. Las reglas de oro del mismo fueron enunciadas por $\mathrm{A}$. Comte en su obra «El discurso sobre el método positivo" y pueden sintetizarse en tres:

- La observación es la única base del conocimiento. Ruptura con la concepción metafísica del universo.

- El estudio científico debe reducirse al análisis de los fenómenos. Ruptura con todo aquello que supone una referencia sagrada al origen o destino.

- La previsión racional. El fundamento de la ciencia sería construir leyes que prevean el futuro.

La base del método positivo sería el razonamiento inductivo, que parte de la observación y mediante clasificaciones y comparaciones se eleva a conclusiones generales y al establecimiento de leyes.

Muy importantes, por las repercusiones que tuvieron en el desarrollo positivista, fueron el avance de la biología y el triunfo del evolucionismo:

- Una primera aportación procedente de la biología fue el triunfo del organicismo. El concepto de organismo (un todo formado por órganos y funciones) comenzó a desbancar a la anterior metodología taxonómica, abriendo las puertas a la epistemología moderna. Estas ideas impregnaron no solo el campo científico, sino, incluso, el ideológico. Así, la burguesía, clase ascendente de la época, no deja de referirse al concepto de cuerpo social y del lugar que cada individuo o grupo social debe ocupar en la sociedad, con vistas a obtener la máxima eficacia.

- La difusión del organicismo se vio potenciada por el triunfo del evolucionismo, que supuso el abandono de la visión estática del mundo y su sustitución por otra dinámica. Estas ideas se afirman con plenitud en la obra de Darwin, con la revolución intrínseca de los nuevos conceptos de selección natural y evolución. La existencia de variables aleatorias en los organismos vivos haría posible que pervivieran los más aptos en la lucha por la vida. Se pasaba, así, de una economía natural, con una proporción 
fija de especies animales y vegetales en cada territorio, a otra, donde el equilibrio se alcanzaba como resultado de la competencia y la lucha de las especies junto a la selección. Esta nueva visión fue la causante de la aparición, en el panorama científico, de una nueva ciencia: la Ecología.

Fue, precisamente, en este caldo de cultivo científico, donde surgió la primera gran corriente geográfica, que denominaremos ambientalismo. Las ideas fundamentales de esta corriente del pensamiento geográfico contemporáneo enlazan con la filosofía positivista y las obras de Darwin y Stackel. Pronto se establece un paralelismo entre la conducta animal y humana y se llega a la conclusión de que los hombres se hallan controlados por leyes naturales. Este traspaso de la biología a la ciencia social fue general, pero tuvo en el campo geográfico la virtud de unificar las dos ramas de la Geografía (Física y Humana) en una sola, ya que el hombre sería el fruto de la tiranía del medio natural. La temática geográfica de aquellos años es fiel reflejo del nuevo paradigma dominante: la determinación del carácter humano por el clima, etc.

\section{El pensamiento geográfico de base historicista}

A finales del siglo pasado, se produjo la reacción frente al positivismo y el naturalismo, poniéndose en entredicho principios aceptados hasta entonces como indiscutibles. El rechazo del monismo positivista vino de la mano de Kant y supuso la división del conocimiento científico en dos tipos de ciencias muy diferentes, tanto en la especificidad de sus objetos de estudio como en la metodología utilizada. En las ciencias de la naturaleza cabe hablar de «explicación», para referirse a relaciones que se entienden de orden causal, mientras que en las ciencias sociales solamente tendría cabida el concepto de “comprensión», en un orden científico diferente, no determinista, donde el individuo humano es el agente y hacedor de su presente y futuro, interviniendo decisivamente en la transformación del medio.

El triunfo de la corriente historicista cristalizó en el campo geográfico en el triunfo del posibilismo o historicismo, como nuevo paradigma triunfante. Los grupos humanos se consideran, desde esta nueva perspectiva, instalados en el medio natural, que ya no tiene un carácter absoluto sino relativo. La libertad humana sería capaz de modificar el medio y de elegir entre diversas opciones.

En esta situación de ruptura, la Geografía encontró, en el estudio regional, la forma unir, de nuevo, los campos derivados de la tradicional 
dicotomía: físico-humano. La región se concebiría como un espacio de características físicas, naturales y culturales semejantes, que se diferenciaria de los espacios contiguos, por el distinto proceso de gestación, donde cada espacio regional sería modelado por la relación íntima y estrecha de los individuos y el territorio a lo largo del tiempo.

\subsection{Las corrientes geográficas de la etapa contemporánea}

\section{La aportación geográfica neopositivista}

A partir de los años cincuenta de nuestro siglo, la Geografía conoció una profunda conmoción en el mundo anglosajón, que originó el paradigma cuantitativo. Geógrafos cuantitativos y cualitativos se enfrentaron en una confrontación que oponía, frontalmente, teorías, métodos y técnicas de investigación. El triunfo de las nuevas ideas partía de una visión optimista de la vida, que impulsaba el desarrollismo económico de aquellos años. Las ciencias eran consideradas como dirigidas a la resolución de los problemas concretos de la sociedad, desde una posición tecnicista, y el resultado fue la separación de la misma en compartimentos estancos, lejos de una visión integradora de la realidad.

El paradigma cuantitativo apoyaba y fundamentaba su razón de ser y sus métodos en el positivismo lógico, basado en las ideas de la Escuela de Viena, que consideraba que la lógica formal y las matemáticas, así como la evidencia de los sentidos, son las únicas vías seguras del conocimiento.

La visión de K. Poper modificó, sustancialmente, el método de investigación del positivismo decimonónico, por un nuevo neopositivismo, basado en el triunfo del planteamiento hipotético-deductivo. La elaboración de teorías, más que la recogida de la información, se consideraba clave en el acceso al conocimiento científico. El cambio es, sin duda, radical. La observación y el trabajo empírico aparecen al final de la investigación, como corroboradores de la teoría construida, y no al contrario, como sucedía en la metodología inductiva, hasta entonces imperante.

Diversas características definen el nuevo paradigma científico, aplicable, tanto a las ciencias naturales como sociales:

- La posibilidad de transferir teorías de un campo a otro y de usar un lenguaje común en todas las disciplinas. Así, las regularidades que se encuentran en la Física se pueden descubrir en otros órdenes de la realidad. Esta circunstancia originó la denominada «física social». 
- Las leyes no tienen porqué ser causales. La teoría de la probabilidad contribuyó al desarrollo de los procesos estocásticos no deterministas.

- La reformulación de la metodología científica sobre la base de la construcción de modelos. Los modelos hipotético-deductivos se elaboraron de acuerdo a las siguientes fases:

- Definición de una serie de supuestos básicos simplificadores de la realidad.

- Deducción del modelo teórico por razonamiento lógico.

- Comprobación experimental del modelo, de acuerdo al material empírico disponible.

- El orden científico descubierto se presuponía ahistórico.

La nueva corriente geográfica que sintoniza con estos planteamientos epistemológicos ha sido definida como cuantitativa o neopositivista. La aplicación al campo geográfico de las ideas presentes en el neopositivismo condujo al desarrollo de nuevas problemáticas, como la localización espacial de las actividades económicas, las regularidades espaciales de la distribución de la población, etc. La definición de modelos geográficos como el de Von Thunen, el de W. Christaller, se hallaban en la línea descrita, donde la definición de unos presupuestos de partida (llanura isotrópica, homo economicus, etc.) daban base a la concreción de los modelos espaciales, como cristalización de las teorías de base geográfica.

Desde la perspectiva de la Teoría General de Sistemas se ha tendido a romper con la elaboración de modelos estáticos y de equilibrio final, mediante una visión más dinámica de la realidad Se podría definir al sistema, elemento fundamental del nuevo paradigma, aunque, igualmente, de base cuantitativa, como al "conjunto delimitado de componentes, dotados de ciertas propiedades, atributos o valores, todos los cuales están en relaciones directas o indirectas de interdependencia y acoplamiento, cumplen unas funciones y están implicados, de algún modo, en la producción de un resultado final o al menos de su mantenimiento".

Según esta definición habría que destacar dentro del nuevo paradigma sistémico los siguientes aspectos:

- El sistema está integrado por elementos.

- Cada elemento tiene unas determinadas propiedades y cumple una función específica.

- Cada elemento mantiene una relación con los demás (interrelación).

- Los diversos elementos producen un resultado. 


\section{El nuevo paradigma behaviorista}

Durante la década de los años sesenta, al mismo tiempo que se imponía el optimismo neopositivista, comenzaban a dejarse sentir voces insatisfechas, cuestionando los aspectos esenciales de tal concepción científica. Una serie de condicionamientos políticos, sociales y económicos (acceso a la independencia de gran número de países, guerra de Vietnam, florecimiento del marxismo, deterioro de las condiciones de vida urbana y del medioambiente, cuestionamiento de la neutralidad de la ciencia, etc.) comenzaron a atisbar un momento de crisis en el sistema capitalista. La crisis se tradujo en la proliferación de movimientos críticos y radicales y, al mismo tiempo, en el descubrimiento de la dimensión psicológica y una nueva valoración de la experiencia personal, que contribuyó a cuestionar los abstractos enfoques neopositivistas, generando un gran interés por las corrientes fenomenológicas y existencialistas.

Cada una de estas circunstancias generaria una nueva corriente geográfica. La Geografía del Comportamiento y de la Percepción surge dentro del nuevo paradigma behaviorista, versión, en nuestra disciplina, de la corriente conductista. El comportamiento del hombre era considerado como muy alejado del comportamiento racional del homo econornicus, considerándose, según los nuevos planteamientos, condicionado por el medio social y otros factores externos. La conducta humana vendria, así, condicionada por la imagen mental previa que el hombre posee del medio que le rodea.

La imagen (Geografía de la Percepción) sería para el geógrafo el filtro que se interpone entre el hombre y el medio y su preocupación sería analizarla, comparando su isomorfismo con el del mundo real. El hombre, al percibir el medio a través de los sentidos, ha de interpretar los diversos componentes que aparecen en el campo de su percepción. La estructura de los objetos percibidos varía de un individuo a otro, aunque podríamos referirnos a estructuras derivadas de los grupos sociales, por su cultura, etc. Por su parte, la Geografía del Comportamiento estudiaría como el hombre reacciona frente al medio con su limitado conocimiento de la realidad.

\section{La corriente geográfica radical}

El rechazo del neopositivismo fue realizado también desde movimientos radicales, que cuestionaban la excesiva especialización de las ciencias sociales como defensoras del estatuquo existente. Se pretendía la elaboración de una teoría general más comprensiva de la realidad, una ciencia holística con un objetivo esencial: elaborar teorias sociales desde el análisis de una realidad histórica concreta. 
En este contexto, se desarrolló la nueva corriente geográfica radical. Su principal objetivo se dirigía a poner al descubierto la falsa cultura, implicando a la ciencia, en general, y a los geógrafos, en particular, en los problemas de la desigualdad social y la lucha política. El órgano del movimiento fue la revista "Antipode" de la universidad de Worcester, desde donde se difundió al resto de las universidades americanas.

La Geografía Radical se decantó en dos grandes grupos o corrientes, por su ideología afín:

- Los radicales liberales, que combinaban su fe en la democracia con la acción para cambiar las situaciones de injusticia social, en la creencia de que el propio sistema capitalista podría permitirlo.

- Los radicales marxistas y anarquistas, convencidos de la necesidad de transformar el propio sistema.

La temática geográfica varió radicalmente en el campo de este nuevo paradigma geográfico. La idea de que el espacio es un producto social implica necesariamente partir de la estructura social para conocer la organización del espacio. Así, la investigación geográfica derivó a diferentes focos de interés: elaboración de una teoría general de al ciudad y del espacio (D. Harvey, M. Castell, etc.), el análisis de las condiciones de vida de los grupos marginados, etc.

\section{La corriente geográfica humanista}

Finalmente, la reacción antipositivista inspiró otra gran corriente del pensamiento geográfico: la corriente humanista. La Geografía humanista propone un nuevo marco de análisis de la realidad a partir del conocimiento que procede de la experiencia vital de cada individuo. Este planteamiento enlaza con las corrientes fenomenológicas y existencialistas del pensamiento humano.

Desde esta nueva perspectiva, el espacio interesa como espacio afectivo y subjetivo. Se trataría de conocer los mecanismos íntimos que unen al hombre con la naturaleza, para, a continuación, trazar los rasgos básicos del espacio vivido por cada individuo o grupo social.

\section{PRINCIPALES MODELOS DEL APRENDIZAJE EDUCATIVO}

El desarrollo de la Psicología Evolutiva ha puesto de manifiesto la importancia del conocimiento sobre como el alumno asimila la materia objeto 
de estudio. La construcción de un edificio didáctico, basado únicamente en la estructuración de objetivos, contenidos y métodos, alejado de la lógica del aprendizaje del alumno, se ha revelado como una estrategia educativa equivocada. Si el núcleo fundamental de la respuesta didáctica se cimentara en como transmitir adecuada y exclusivamente a los alumnos un tipo de contenidos que se consideren significativos, en función de una hipotética lógica interna de la ciencia, las posibilidades de éxito en el proceso de la enseñanza se vería, sin duda, reducido.

Desde esta perspectiva, la elaboración de un curriculum escolar, con ser importante, necesita de la aportación complementaria sobre el conocimiento psicológico de la interacción con los alumnos. Resulta, por tanto, imprescindible trazar, aunque sea de forma sintética, la panorámica de las tendencias dominantes en el campo de la Psicología aplicada a la educación, como fuente de conocimiento sobre posibles soluciones que integren, de forma armónica, la lógica interna de la ciencia con la propia del aprendizaje. Nos vamos a referir, en relación con la Geografía, a las tres tendencias que consideramos dominantes: la conductista, la cognitiva y la ecológica.

El conductismo se basa en un concepto positivo de la ciencia, fundamentado en la asociación estímulo-respuesta. Según esta teoría del aprendizaje, el profesor se convierte en un emisor de conceptos que el alumno debe aprender, sin aportar una reacción constructiva desde su parte que complemente el proceso educativo.

La presunta complejidad de la transmisión de conocimientos se reduce, desde la posición de la teoría conductista, al simplificar y reducir toda conducta, por compleja que sea, a una serie de asociaciones entre elementos simples o nuevas relaciones de tipo estímulos y respuestas (Pozo, J.I., 1989). Esta posición pedagógica se limita a construir un conjunto de objetivos (conductas) y actividades, programadas de forma completa para todos los alumnos, que sivan de pauta para comprobar como el alumno se acerca, positivamente, a las metas previamente planificadas. Las respuestas positivas serian recompensadas con las calificaciones positivas, necesitándose de técnicas de refuerzo para aquellos alumnos que no alcanzaran los objetivos previstos. Este esquema del aprendizaje muestra la consideración pasiva del alumno en el proceso didáctico y su ausencia de participación creativa.

Desde los años sesenta, comenzaron a surgir nuevas alternativas al modelo conductista, basadas en las teorías sobre el procesamiento de la información, que consideraban a la inteligencia humana como una potencia capaz de procesar y estructurar la información. Las nuevas teorías cognitivas partían de una analogía clara entre el hombre y el ordenador (Friera Suárez, F., 1995). El individuo humano podia ser considerado con 
capacidad para recoger información del medio, procesarla y dar respuestas personales, en función de algún cómputo operado en su interior. $\mathrm{El}$ esquema operativo cognitivo da un giro de 180 grados, respecto al conductista. El alumno sería capaz de elaborar procesos mentales a partir de una información recibida y reaccionar con respuestas inteligentes activas.

Esta visión dinámica de la interacción educativa profesor-alumno sería complementada por la aportación de la Psicología Evolutiva. El pensamiento y la inteligencia, tal como expresa Piaget (Piaget, J., 1984), autor destacado de esta nueva teoría constructivista del aprendizaje, se manifestarían en estados o etapas diversas a lo largo de la vida. Cada estado vendria caracterizado por una organización mental, que capta los conceptos de forma diferente. Las principales etapas o niveles de desarrollo en el niño serían: el sensoriomotor (de 0 a 2 años), el intuitivo o preoperatorio (de 2 a 7 años), el operatorio concreto (de 7 a 11 años) y el operatorio lógico (de 11 a 15 años). Las concepciones de la realidad serían propias del estadio evolutivo y su conocimiento resulta determinante si deseamos comprender la correspondencia entre los conceptos planificados para el aprendizaje y la posible respuesta de los alumnos, según su etapa de desarrollo.

El planteamiento cognitivo planteaba que la conducta humana, como consecuencia del proceso de enseñanza-aprendizaje, se realizaría sin tener en cuenta la relación con el medio o contexto social alguno. Con el objetivo de ofrecer nuevas alternativas, el modelo ecológico presenta un esquema interpretativo que propone que la respuesta del individuo está dirigida por su adecuación al ambiente.

Este nuevo modelo educativo enlaza con las ideas de Vygotski (Vygotski, L.S., 1989), que defiende la influencia del entorno y del ambiente social y cultural en el aprendizaje. En este sentido, el alumno no estaría solo en el momento de aprender, sino que su entorno más inmediato, sería vital para su desarrollo. La relación con otros alumnos, no solo con el profesor, favoreceria su nivel de desarrollo, al plantearse la respuesta educativa de forma colectiva y no individualizada. Así, los profesores, los compañeros, la escuela, el barrio y la localidad se convierten en mediadores efectivos de una cultura contextualizada.

\section{LA RELACIÓN ENTRE LAS CORRIENTES GEOGRÁFICAS Y LAS TENDENCIAS EDUCATIVAS. APLICACIÓN AL CAMPO DE LA GEOGRAFIA URBANA}

Las diversas corrientes geográficas nos han servido para acotar la materia geográfica, desde la perspectiva de la lógica de la ciencia en sí. Por 
su parte, la existencia de modelos educativos nos muestra el camino de cómo acometer la tarea de la enseñanza, desde diferentes posiciones de la Psicología del Aprendizaje. Ambos planteamientos, con objetivos, sin duda, muy distintos entre sí, se entrelazan, como no podía ser de otra manera, como consecuencia del momento histórico en que surgen. Así, el esquema conductista de la educación sintoniza, en gran manera, con la posición de la Geografía de la Percepción y del Comportamiento, al establecer que el comportamiento es una respuesta inmediata frente a la imagen o estímulo. En el mismo sentido, la Geografía Cuantitativa enlazaría con el modelo cognitivo, en cuanto los modelos lógicos y matemáticos del espacio requieren un nivel de comprensión personal, propio de este planteamiento educativo. $\mathrm{O}$, finalmente, las tendencias ambientalista, historicista, radical y humanista, aunque de forma diferente, se acomodarían mejor al enfoque didáctico ecológico, que muestra como el aprendizaje se desarrolla en un medio o entorno determinado.

En líneas generales, podriamos concluir que las tendencias geográficas influidas por el historicismo son desarrolladas, a nivel educativo, por el enfoque ecológico y las procedentes del positivismo lo son por el enfoque cognitivo. Todo ello, sin olvidar otras relaciones concomitantes, como la influencia del conductismo en la propia Geografía Cuantitativa y la Geografía de la Percepción y del Comportamiento (Herrero Fabregat, C., 1995). Una relación entre las principales tendencias geográficas y educativas podemos observarla en el cuadro adjunto.

Cuadro I. Relación entre las principales tendencias geográficas $y$ educativas

\begin{tabular}{ll}
\hline Tendencias geográficas & Tendencias educativas \\
\hline Ambientalista & Ecológica \\
Regionalista & Ecológica \\
Cuantitativa & Cognitiva \\
Percepción & Conductista y Cognitiva \\
Radical & Ecológica e Interaccionismo social \\
Humanista & Ecológica \\
\hline
\end{tabular}

Fuente: Herrero Fabregat C., 1995.

Con objeto de estudiar el acomodo existente entre las tendencias geográficas y educativas, hemos seleccionado el campo de la Geografía Urbana, tratando de mostrar, con varios ejemplos, cómo materias de estudio, que participan en determinados curricula de la ciencia geográfica, 
como si fueran neutros e intercambiables, son, en realidad, componentes homogéneos en sí mismos y heterogéneos entre sí. Su integración, como habitualmente se hace, en un programa que los mezcla, deberia, al menos, plantearse la adecuación teórica, metodológica y de modelo didáctico a los alumnos a los que va dirigida.

Para ayudar a su exposición, hemos seleccionado seis ejemplos de contenido didáctico variado, cuyo origen se acomoda a los principales paradigmas de la ciencia geográfica que fueron desarrollados con anterioridad. Además, hemos estructurado su contenido en tres apartados semejantes, en todos los casos: relación con el paradigma del cual procede, adecuación al modelo didáctico en que se inserta y algunas estrategias didácticas sobre conceptos, problemáticas y métodos de trabajo que pueden desarrollarse.

\subsection{Los modelos ecológicos de la ciudad}

1. Relación con el paradigma geográfico dominante, del cual procede

Este tipo de modelos encuentran su acomodo epistemológico en el paradigma ambientalista del determinismo geográfico. La consideración de que el comportamiento humano se adapta a los procesos del mundo subsocial enlaza con las ideas próximas al positivismo y evolucionismo biológico decimonónicos. La organización espacial de los grupos humanos en la ciudad debe ser comprendida como una relación de causa-efecto, obedeciendo a leyes naturales, con una respuesta semejante a la de las comunidades animales o vegetales. El propio concepto de comunidad vacía de contenido social a lo humano, reduciéndolo al puro orden biológico, lo que lleva implícito una relación ecológica frente al medio desprovista de toda conciencia y capacidad personal. Los modelos ecológicos muestran su relación directa con el evolucionismo darwinista. El hombre deja de ser el centro del universo y se convierte en pura necesidad evolutiva.

\section{Adecuación al modelo didáctico en el que se inserta}

Los modelos urbanos de al escuela de Chicago se pueden relacionar directamente con el enfoque ecológico en educación. El medio se convierte en el agente esencial y motor capital de toda la evolución y comportamiento de los seres vivos. El aprendizaje tendría, además, un fuerte componente conductista, ya que se trata de transmitir, cómo determinadas conductas del mundo subsocial se plasman en regularidades geométricas de orden espacial. 
El contenido de aspectos lógico-formales traspasa la capacidad de los alumnos menores de 12 años, por to que debe tenerse presente a la hora de su programación. La dificultad de su comprensión se basa en la necesidad de establecer conexiones de causalidad entre los procesos biológicos en que se fundamentan y las manifestaciones de regularidad en la distribución espacial de los grupos humanos, según su actividad. Estas regularidades deben matizarse según los principios en que se apoyan los diversos modelos existentes (Burgess, Hoyt y Harris y Ullman, entre otros).

\section{Estrategias didácticas del aprendizaje}

La enseñanza de los modelos ecológicos de la ciudad se debe realizar, definiendo, de antemano, el marco ecológico donde estas teorías surgen. La inclusión de la Ecología Humana como una rama de la Ecología, en general, debe mostrar como el comportamiento del hombre en su medio tiene lugar como comunidad humana, desde la cual, establecer la analogía con las comunidades animales y vegetales.

La exposición de los modelos ecológicos de la ciudad (modelo de las áreas concéntricas, modelo sectorial, modelo de los núcleos múltiples, etc.) requiere, previamente, de la de los procesos biológicos, tal como son adaptados al mundo subsocial. El proceso de competencia, que en el caso del hombre tiene lugar por la localización más ventajosa de las actividades en el espacio de la ciudad; el proceso de dominación, con el establecimiento de un área dominante, como el C.B.D.; y, finalmente, el proceso de invasión-sucesión, que permite delimitar los mecanismos de transformación del carácter espacial, previamente definido. Una vez delimitados los mecanismos de funcionamiento de la acomodación de las especies (actividades o grupos sociales, en el caso de la comunidad humana) es cuando se debe exponer, detalladamente, las regularidades geométricas que se derivan de los principios anteriormente expuestos.

\subsection{La ciudad historicista}

1) El estudio historicista de la ciudad sintoniza con la corriente geográfica del mismo nombre, próxima al posibilismo geográfico. Desde esta perspectiva epistemológica, la ciudad, frente a la posición del planteamiento anterior, sería el fruto de una organización social concreta, consecuencia de la acción humana. Este circunstancia conlleva la máxima implícita en el posibilismo geográfico: "el hombre dispone sobre aquello que 
la naturaleza permite" (Claval, P., 1974) y es capaz de transformar el medio en un sentido no predeterminado de antemano. No cabe hablar, por tanto, de leyes geográficas, sino del acontecer histórico, donde el hombre en sociedad modela el espacio según cadencias siempre definidas pero pocas veces iguales.

Este concepto de lo urbano tendría un carácter dinámico, que enlaza con el concepto, dominante en el pensamiento historicista, de fenómeno urbano. De acuerdo con ello, la ciudad no debe ser concebida como algo ya definido y fijo, sino como una entidad en proceso constante de transformación, reflejo de cada forma particular de civilización. Este proceso de urbanización, creciente en todo el mundo, habría seguido caminos diversos, en función del desarrollo económico de cada país e incluso de sus propias tradiciones culturales e ideologia política.

2) Este posicionamiento teórico de la ciudad enlaza con el modelo didáctico de raigambre ecológica. La problemática implícita a la ciudad historicista se presta al estudio concreto de su entorno: la región. Sobre la base del conocimiento de un espacio urbano concreto, se pueden desarrollar actividades educativas dirigidas a comprender los aspectos teóricos y conceptuales, desde el interés suscitado por el conocimiento de lo concreto. Posteriormente, la maduración conceptual puede traspasarse a otros espacios geográficos más amplios, menos conocidos, donde los ejemplos propuestos caminen de lo particular a lo general, con explicaciones basadas en la historia de cada ciudad.

3) El estudio historicista de la ciudad permite programar la estrategia educativa, aprovechando el orden temporal, según el cual, el desarrollo de los acontecimientos históricos habría ido modelando el espacio urbano objeto de análisis. De acuerdo con ello, de forma secuencial, las principales fases de ese proceso educativo serían:

- Definir las principales etapas históricas (preindustrial, industrial y postindustrial) de las sociedades contemporáneas, concretando las actividades sociales y económicas fundamentales por ellas desarrolladas, haciendo hincapié, de forma general, en el papel desempeñado por la ciudad, en cada periodo histórico, en la organización del territorio.

- Precisar los conceptos de situación y emplazamiento urbanos como resultado de la interacción de factores físicos (topografía, lugares de ruptura de carga, proximidad del agua, etc.) e históricos, que expliquen el porqué del lugar primitivo ocupado por la ciudad.

- Delimitar los conceptos de morfología, función y estructura urbanas, a partir de las diversas tramas de los planos urbanos, según el momento 
de la génesis urbana, así como de la especialización del espacio de la ciudad (función y uso del suelo urbano) en el desarrollo de una actividad determinada y su relación mutua (estructura).

- Desarrollar el concepto de región urbana, como hinterland o área de influencia de una ciudad, de acuerdo a las relaciones que mantiene con el espacio circundante. Definir los diferentes tipos de áreas existentes (suburbana, periurbana, etc.).

- Finalmente, definir el concepto de desarrollo urbano, a partir del crecimiento de una ciudad, observando la evolución de la trama y estructura urbanas, de acuerdo a las etapas históricas que se han ido sucediendo a lo largo del tiempo. Mostrar las peculiaridades según contextos históricos contrastados.

\subsection{Los modelos urbanos neopositivistas}

1) La preocupación teórica de la Geografía Neopositivista por la medición y el establecimiento de leyes de carácter hipotético deductivo afectó al estudio de la ciudad, originando una proliferación de modelos urbanos según los cánones propuestos.

Para los geógrafos defensores de esta posición teórica, la temática urbana prescinde de consideraciones genéticas e históricas, para centrarse en las relaciones espaciales de los elementos de la ciudad (usos del suelo, principalmente) o de las ciudades entre si, de manera formal. Interesa establecer, de forma precisa, la posición relativa de cada espacio urbano según la actividad, los valores del suelo respecto a los lugares centrales o vías de acceso, etc., generalizando la localización relativa en un modelo, expresión máxima del orden espacial en la ciudad, que muestra la realidad urbana de manera ahistórica.

Los modelos más interesantes, desde la óptica de la didáctica geográfica de la ciudad, son los modelos economicistas, de corte clásico, estáticos, que, en la línea del modelo de Von Thunen, expresan la disposición de los usos del suelo en la ciudad a partir de un conjunto de presupuestos de partida. También es de destacar, por su importancia en el desarrollo de la ciencia geográfica, el modelo de W. Christaller, que construido de acuerdo a premisas semejantes, establece, deductivamente, la disposición espacial óptima de las ciudades en la distribución de bienes y servicios.

2) El método hipotético deductivo aparece como el vehículo activo fundamental en la enseñanza activa propuesta para el desarrollo de las acti- 
vidades docentes de la ciudad cuantitativa. La capacidad de abstracción, que tal procedimiento lleva implícito debe desarrollarse a partir de los 1112 años, según el modelo docente cognitivo, por lo que debe tenerse muy presente al elaborar curricula geográficos que integren esta materia de estudio.

Este modelo didáctico, aplicado al estudio de la ciudad, se presta al empleo de los juegos de simulación, donde la resolución de una determinada situación real o hipotética, mediante la toma de decisiones de los participantes, de acuerdo a unas reglas previamente establecidas, favorece el aprendizaje de forma activa y motivadora. Los denominados juegos de localización, en los que los alumnos buscan la localización óptima para una determinada empresa comercial o industrial, o los de construcción de ciudades, en la línea de trabajar en grupos para modelar una ciudad (Bailey, P., 1981), son algunos ejemplos de la posibilidad de su aplicación. La utilización del ordenador, como recurso didáctico del mayor interés, ha propiciado el desarrollo de este tipo de juegos.

3) El desarrollo didáctico de la ciudad cuantitativa se apoya en el estudio de los modelos. De forma selectiva nos vamos a centrar en algunos de ellos, a los que hemos hecho referencia en apartados anteriores.

Los modelos urbanos hipotético-deductivos, economicistas, sobre la distribución de usos del suelo en la ciudad, exigen la definición previa de los presupuestos de partida (comportamiento racional del homo economicus, llanura isotrópica, costos de transporte proporcionales a la distancia, recursos distribuidos homogéneamente por el espacio, etc.), para, a continuación, exponer la capacidad de renta urbana de cada uso del suelo y el proceso de competencia de los mismos, que determina su posición relativa entorno al espacio central, de mayor valor relativo.

El modelo de W. Christaller asume gran parte de los presupuestos anteriores, añadiendo algunos específicos, como el concepto de lugar central y la organización jerárquica de los centros urbanos en el espacio. A partir de aquí, los conceptos de alcance y umbral, que expresan la capacidad de competencia de cada lugar central (según nivel jerárquico), sirven de puente para expresar la regularidad de la distribución espacial de las ciudades.

Este tipo de modelos ayuda a comprender los principios básicos en que se fundamentan las regularidades espaciales deducidas en los mismos: importancia de la distancia, matizada por la fricción del espacio, lo que introduce el concepto de accesibilidad geográfica; carácter focal de las distribuciones espaciales, respecto a un centro o lugar de máxima accesibilidad; jerarquía de lugares, etc. 
4.4. Los modelos perceptivos de la realidad urbana (el modelo de Lynch)

1) Los modelos perceptivos de la ciudad se apoyan en el paradigma behaviorista de la ciencia geográfica. Para el habitante de la ciudad, según esta concepción epistemológica, no existiría una realidad urbana objetiva, sino unas imágenes parciales, mediatizadas por diversos condicionamientos de índole social, cultural y personal. En este proceso cognitivo, intervendrian desde los propios sentidos hasta otros factores más generales, de carácter biológico, cultural o social (sexo, estatus socioeconómico, tiempo de residencia en la ciudad, etc.). El resultado del proceso de percepción sería la visión particular, individualizada en una imagen, esquema o mapa mental de la ciudad. En otra fase ulterior del proceso de toma de decisiones, la imagen serviría de nexo de unión entre el mundo fenomenológico y el comportamental.

Entre los estudios más conocidos, hay que destacar el de la imagen de la ciudad de K. Lynch (Lynch, K., 1966). Según este autor, las personas organizan la información que poseen de la ciudad, a través de un proceso de selección de elementos particulares del paisaje urbano, que estructuran en un mapa mental de la misma.

2) La Geografía de la Percepción y del Comportamiento se caracteriza por la estrecha relación que mantiene con el paradigma conductista de estímulo-respuesta. La imagen captada por el individuo del medio urbano se convierte en el estímulo capaz de explicar su comportamiento y reacción posterior.

De acuerdo a la teoría constructivista de Piaget, el conocimiento del espacio, por parte del niño, sería el fruto de un proceso, con diversas etapas, con un orden espacial específico para cada una de ellas. Dentro de esta elaboración y construcción del espacio se distinguen tres tipos de relaciones espaciales en función de la maduración del individuo: las relaciones topológicas, que únicamente tienen presente relaciones de proximidad, separación, orden, cerramiento y continuidad (propias de la primera fase vital), las relaciones proyectivas, donde los niños son ya capaces de diferenciar los objetos, según su punto de mira y, finalmente, las relaciones euclidianas, más abstractas, que requieren la relación respecto a unos ejes de coordenadas, donde la distancia es fundamental en la definición de los objetos y su estructura (Herrero Fabregat, C., 1995). El conocimiento de la fase en que se encuentra el alumno resulta básico para comprender la organización de su esquema espacial de la realidad, así como para transmitirle conceptos, cuyo fundamento sea el de objetos en el espacio. 
3) La obra de K. Lynch ha sido básica en la legibilidad del espacio urbano desde una estructura integrada y organizada sobre la base de cinco elementos: sendas o itinerarios, bordes o límites, distritos o barrios, nodos e hitos. Las sendas son los ejes de desplazamiento de las personas. Pueden ser calles, paseos, vías de ferrocarril, etc. Los bordes son elementos lineales que separan realidades urbanas contrastadas, de contenido muy diferente (línea de separación de un área industrial y otra residencial). Los barrios son áreas o zonas de cierta identidad para el observador urbano. Los nodos son lugares de confluencia de sendas. Finalmente, los hitos son puntos de referencia importante de la ciudad, que destacan por su carácter simbólico.

La obtención de la información requiere recurrir, ineludiblemente, al método de la encuesta, de modo que la población manifieste su visión subjetiva del lugar donde vive. Un ejemplo de aplicación al espacio urbano de Segovia (García Ballesteros, A. y Bosque Sendra, J., 1989) permite comprender como organizar la información con vistas a reproducir, según el esquema de Lynch, la estructura de la ciudad, subjetivamente diferenciada por sexo, edad y nivel de estudios de los encuestados. Una metodología semejante, podría utilizarse con los alumnos de un cualquier centro escolar.

\subsection{La problemática radical urbana}

1) La nueva visión de la Geografía radical supuso un cambio definitivo respecto al planteamiento neopositivista de la ciencia y cristalizó en abordar una temática diferente, basada en la lucha contra las desigualdades sociales y la pobreza. El anterior individuo, propio de los modelos neopositivistas, se suponía conocedor, de forma abstracta, de la realidad del mercado, ante el que reaccionaba, buscando, generalmente, el máximo beneficio económico. Como contraste, se impone una nueva visión científica que concede a los grupos sociales (ya no el individuo aislado) un peso definitivo en la estructuración de la ciudad.

Las nuevas orientaciones admiten la existencia de conflictos sociales entre los diversos grupos que integran la sociedad, propios de un sistema económico (el capitalista) que tiende a la explotación y marginación de los grupos sociales más débiles. Así, la especulación del suelo, la segregación socioespacial, la congestión del centro de la ciudad, el aislamiento de ciertos barrios periféricos, la insalubridad y el subequipamiento de las áreas de nivel socioeconómico más bajo serían la consecuencia del máximo beneficio, impuesta por los grupos sociales dominantes en la ciudad y en la sociedad. El espacio es concebido más como producto social, fruto del 
conflicto de intereses, que como un espacio neutro, de consenso, donde la racionalidad económica impone un orden estable y benefactor del conjunto de la sociedad.

2) El planteamiento radical de la ciudad enlaza con el modelo ecológico del aprendizaje, concebido como la relación del hombre y el medio social. La adquisición de conceptos se debe realizar a partir del encuentro del alumno con el entorno socioeconómico donde se desarrolla. Como en el caso de la ciudad histórica, aunque desde un planteamiento diferente (el profesor debe ahondar en las situaciones de conflicto social, como origen de la modelación del espacio), el alumno debe analizar el espacio urbano concreto, pasando de evaluar el espacio más inmediato y particular (barrio, distrito, ciudad), al espacio general (otras ciudades menos conocidas).

3) El proceso de aprendizaje de la ciudad, desde la perspectiva radical, debe enseñar al alumno que la sociedad donde vive no es el fruto exclusivo de una racional planificación de lo urbano, sino consecuencia de posiciones, muchas veces enfrentadas, de intereses sociales divergentes. Esta posición, que se debe ahondar y profundizar, de forma positiva, debe tender a crear personas críticas hacia el despilfarro social por un lado y las carencias de otra parte de la sociedad por otro, a la par que tomar conciencia de los problemas medioambientales del mundo en que vivimos.

La temática a tratar es variada: déficit de la vivienda y equipamientos sociales, existencia de áreas marginales donde impera la delincuencia, caos circulatorio, densificación de la ciudad y ausencia de zonas verdes, la contaminación ambiental, etc. La metodología a desarrollar debe partir del conocimiento de la problemática urbana, a partir de las áreas de conocimiento propuestas, mediante el entendimiento de lo que sucede en el entorno más inmediato, realizando excursiones por otras áreas de la ciudad, con el objeto de completar la visión global de la ciudad. La puesta en común de las experiencias acumuladas pueden servir de base, con la mediación del profesor, para profundizar en las causas (mediante la discusión en grupo) que explican el aparente desorden urbano. La labor del profesor resulta fundamental para ayudar a descubrir como las estructuras y formas urbanas descubiertas son la consecuencia de un sistema de funcionamiento basado en la ley de la oferta y la demanda, donde el mercado desempeña un papel decisivo en el orden espacial resultante.

\subsection{La ciudad humanista}

1) Igualmente interesada por los problemas del hombre, la Geografía Humanista rechaza, sin embargo, de los planteamientos radicales, las 
soluciones de carácter político. Sus interesantes propuestas sobre el espacio vivido y los mecanismos que ligan positivamente al hombre con el lugar le confieren un nuevo sello, en la línea de destacar los valores y significados de lo urbano, deducidos de la relación personalizada del hombre y el medio (Estébanez Alvárez, J., 1992).

Lo que interesa al geógrafo urbano, desde el planteamiento humanista, es todo lo que tiene que ver con la relación cotidiana del hombre y la ciudad, sus vivencias personales, su sentimiento, positivo o negativo, con los aspectos físicos y perceptuales de lo urbano, desde una perspectiva existencialista.

2) El modelo de aprendizaje, intrínseco a la visión humanista de la ciudad, se acerca al definido en el planteamiento historicista, de carácter ecológico, de comprender el cambio experimentado por los modos de vida, a través de la historia de cada lugar, aunque centrado y restringido a la significación de los lugares vitales, para los principales agentes de esta transformación: las personas corrientes.

3) El tratamiento didáctico de la ciudad humanista requiere una metodologia basada en la recopilación de imágenes personales de la ciudad, pero no en la línea subjetiva sugerida por la Geografía de la Percepción y el Comportamiento, sino en el correspondiente al plano personal más íntimo. El desarrollo de actividades educativas puede centrarse en el descubrimiento de los lugares de mayor interés para los habitantes de la ciudad, bien deducidos por encuesta o por entrevista directa, con objetivos variados: preocupación por los centros históricos y su rehabilitación, comprensión de los cambios acaecidos en diversas áreas de la ciudad, desde la perspectiva de la significación profunda de los habitantes de cada lugar, etc.

Otra fuente de gran interés, en el tratamiento didáctico de la ciudad humanista, es el de la novela, tanto como fuente de inspiración como por el reconocimiento, en la misma, de descripciones simbólicas de los diferentes espacios que integran la ciudad. De la novela, el geógrafo se informa del vasto alcance que las realidades espaciales tienen, de cómo no se limitan a constituir, exclusivamente, un escenario neutro, sino de cómo intervienen de forma activa en la organización del modo de vida de las gentes (Díaz de Castro, F. y Quintana Peñuela, A., 1984).

\section{BIBLIOGRAFIÁA}

Aldana Fernandez, S. (1982): Didáctica de las Ciencias Sociales. Geografía. Ed. Marfil. Alcoy. 126 págs.

Balley, P. (1981): Didáctica de la Geografia. Ed. Cincel. Madrid. 205 págs. 
Benejam Arguimbau, P. (1991): Aspectos didácticos de Geografia e Historia (Geografia). l.C.E. Universidad de Zaragoza. Zaragoza. 164 pags.

CAPEl, H., Luis, A. y URTEAGA, L. (1987): "La Geografía ante la reforma educativa» en Carretero, M., Pozo, J.I. y Otros: La Geografía y la Historia dentro de las Ciencias Sociales: hacia un curriculum integrado. MEC. Dirección General de Renovación Pedagógica. Madrid, págs. 129-172.

CAPEL, H. (1981): Filosofía y Ciencia en la Geografía Contemporánea. Una introducción a la Geografía. Ed. Barcanova. Barcelona.

Carretero, M. y Pozo, J.I. y Otros (1987): La Geografía y la Historia dentro de las Ciencias Sociales: hacia un curriculum integrado. MEC. Dirección General de Renovación Pedagógica. Madrid. 289 págs.

Claval, P. (1974): Evolución de la Geografia Humana. Ed. Oikos Tau. Barcelona. 240 págs.

Diaz de Castro, F. y Quintana Peñuela, A.(1984): Juán Marsé: Ciudad y Novela. Uitimas tardes con Teresa: Organización del espacio y producción de la imagen. Universidad de Palma de Mallorca. Mallorca, 94 págs.

Dominguez Garrido, C. (1994): Curriculum y Enseñanza de la Geografía en el marco de las Ciencias Sociales. Educación Permanente. UNED. Madrid. 137 págs.

Estébanez Alvarez, J. (1989): Tendencias y problemática actual de la Geografía. Ed. Cincel. Madrid.

Estébanez Alvarez, J. (1992): "Bases para un diseño curricular de la Geografía en la enseñanza secundaria" en Monclús Estella, A. (Coord.): La enseñanza de la Historia, la Geografia y las Ciencias Sociales. Ed. Complutense. Madrid. 162 págs.

Freiera Suarez, F. (1995): Didáctica de las Ciencias Sociales. Geografia e Historia. Ed. De la Torre. Madrid. 286 pags.

Garcia Ballesteros, A. y Bosque Sendra, J. (1989): El espacio subjetivo de Segovia. Ed. Universidad Complutense. Madrid. 127 págs.

Garcia PeRez, F. (ED.) (1991): Didáctica de las Ciencias Sociales: Geografía o Historia. Estado de la Cuestión. Universidad de Sevilla. Sevilla. 131 págs.

Graves, N.J. (1988): Reflexiones sobre la enseñanza de la Geografía y la Historia en el Reino Unido y en España. Documentos Didácticos. ICE. Universidad de Salamanca. Salamanca, 118 págs.

GUREVISCH y otros (1995): Notas sobre la enseñanza de una Geografia Renovada. Ed. Aique. Buenos Aires. 96 págs.

HerRero FABREgAt, C. (1995): Geografía y Educación. Huerga y Fierro editores, Madrid. 153 pags.

Johnston, R.J. (1979): Geography and Geograhers. Anglo American Human Geography since 1945. Ed. Arnold. London.

KHeN, T.S. (1979): La estructura de las revoluciones cientificas. Ed. Fondo de Cultura Económica. Madrid. 319 págs.

Luis Gomez, A. y Guijarro Fernandez, A. (1992): La enseñanza de la Geografia. Guia Introductoria. Universidad de Cantabria. Santander. 298 págs.

LYNCH, K. (1966): La imagen de la ciudad. Ed. Infinito. Buenos Aires.

Monclús Estella, A. (Coord.) (1992): La enseñanza de la Historia, la Geografía y las Ciencias Sociales. Ed. Complutense. Madrid. 162 págs.

Moreno Jiménez A. y MARRón Gaite, M.J. (1995): Enseñar Geografía. Ed. Sintesis. Madrid. 397 págs.

Pérez Martinez, J.J. y otros (1995): Didáctica de Geografía e Historia. Ed. Complutense. Madrid. 278 págs.

PIAGET, J. (1984): La representación del mundo del niño. Ed. Morata. Madrid.

Pozo, J.I. (1989): Teorias cognitivas del aprendizaje. Ed. Morata. Madrid.

SANTOS Preciado, J.M. (1992): «El desarrollo de la Geografía Urbana en la evolución del pensamiento geográfico contemporáneo" en Espacio Tiempo y Forma. UNED, Madrid. págs. 9-40.

- (1996): "Recursos informáticos y enseñanza de la Geografía" en Didáctica Geográfica. Universidad de Burgos. Burgos, págs. 57-66.

- (1997): "Los sistemas de información geográfica (S.I.G.): un recurso docente en la enseñanza de los modelos de localización geográficos". La informática desde la perspectiva de los educadores. UNED. Madrid, págs. 873-878.

VYGotski, L.S. (1989): El desarrollo de los procesos psicológicos superiores. Ed. Crítica. Barcelona. 